\title{
Influence of condition on behavior and survival potential of a newly settled coral reef fish, the bluehead wrasse Thalassoma bifasciatum
}

\author{
Kirsten Grorud-Colvert*, Su Sponaugle \\ Marine Biology and Fisheries Division, Rosenstiel School of Marine and Atmospheric Science, University of Miami, \\ 4600 Rickenbacker Causeway, Miami, Florida 33149-1098, USA
}

\begin{abstract}
For newly settled coral reef fishes, survival advantages may be associated with specific early life history traits or condition levels that lead to differences in behavior. To identify physiological and behavioral characteristics associated with different condition levels, bluehead wrasse Thalassoma bifasciatum recruits were collected immediately after settlement from reefs in the upper Florida Keys, USA, and transported to the laboratory for experimental analysis. Quantification of swimming capabilities was coupled with otolith analysis to identify early life history traits associated with swimming performance. Fish with the highest critical swimming speeds were those that grew faster as larvae, had shorter pelagic larval durations, and were smaller at settlement, although these individuals represented only $10 \%$ of the total sample. To further investigate condition-associated behaviors, a feeding treatment established fish of 2 different condition levels for comparison. Recruits fed for $1 \mathrm{wk}$ at higher levels grew faster, had greater standardized weight (Fulton's condition factor), and swam faster than food-deprived recruits. In additional behavioral trials, high condition recruits evaded a simulated predator threat at faster speeds than the low condition recruits. High condition fish also exhibited less risk-taking behavior by sheltering more in the presence of a predator threat and consuming less food. For both high and low condition recruits, the number that sought shelter increased and food consumption rates decreased in the presence of a predator threat. These results link early life history traits and physiology with associated condition-based differences in behavior, likely underlying the observation that mortality in $T$. bifasciatum is frequently selective for condition.
\end{abstract}

KEY WORDS: Reef fish condition - Survival advantage $\cdot$ Early life history traits $\cdot$ Critical swimming speed $\cdot$ Juvenile behavior $\cdot$ Foraging $\cdot$ Predator evasion

\section{INTRODUCTION}

Predation is one of the major processes affecting the settlement and subsequent population dynamics of juvenile coral reef fishes (Hixon 1991, Carr \& Hixon 1995, Hoey \& McCormick 2004). Even relatively small differences in mortality and growth rates during the larval stage can lead to large fluctuations in fish recruitment (Houde 1987). These rates can be influenced by particular traits that enhance the survival probability of specific individuals within a population (Sogard 1997). For example, the growth-mortality hypothesis (Anderson 1988, Sogard 1997) states that surviving young fish are often those able to grow faster, attain larger sizes, and reduce the duration of early, more vulnerable stages. Larger individuals will have a greater chance of evading gape-limited predators ('bigger is better' concept, Miller et al. 1988), and faster growing recruits will attain larger sizes more quickly, thereby escaping predation through a size refuge ('growth-rate' concept, Bailey \& Houde 1989). Recruits that settle to the reef more quickly reduce losses due to intense predation during the pelagic stage ('stage duration' concept, Anderson 1988). 
Indeed, studies indicate that larger size or faster growth of larvae can lead to enhanced recruitment or juvenile survival (Searcy \& Sponaugle 2001, Bergenius et al. 2002, Shima \& Findlay 2002, Vigliola \& Meekan 2002, McCormick \& Hoey 2004, Sponaugle et al. 2006).

However, size and growth-selective mortality may not be the only processes affecting survivorship of newly settled reef fishes. For example, no evidence of size-selective mortality was found in field studies investigating the effect of predation on juvenile bluehead wrasse Thalassoma bifasciatum (Carr \& Hixon 1995) and goatfish Upeneus tragula (McCormick \& Molony 1993). Growing evidence suggests that condition, measured physiologically as lipids, proteins, carbohydrates, standardized weight, or cell vacuolation (e.g. McCormick \& Molony 1993), may play a role in survival (Booth \& Hixon 1999, Searcy \& Sponaugle 2001, Booth \& Beretta 2004, Hoey \& McCormick 2004). Fast growth is frequently associated with high condition; thus, growth rates obtained from otoliths can also provide a historical record of condition (Searcy \& Sponaugle 2001, Shima \& Findlay 2002, Sponaugle \& Pinkard 2004). Variable condition can lead to differences in behavior, such as swimming and foraging (Stobutzki 1997, Green \& McCormick 1999, Sogard \& Olla 2002). Swimming capability associated with higher condition can indicate increased response or quicker evasion during predator attacks (Chick \& Van den Avyle 2000). Differences in foraging rates mediated by the threat of predation could lead to one of several outcomes. Fishes may (1) increase the rate at which they feed to compensate for lost foraging time, (2) decrease the rate at which they feed to maintain greater anti-predator vigilance, or (3) not alter their rate of foraging (Lima \& Dill 1990). To obtain sufficient food, recruits with lower condition may take greater behavioral risks, increasing their vulnerability to predation (Holbrook \& Schmitt 1988, Sogard 1997, Pressier et al. 2005). Recruits with higher condition may be able to survive for longer periods of time by using greater energy reserves to mediate the effects of lost foraging time due to the threat of predation (Lima \& Dill 1990). Evaluation of the non-lethal effects of predation, such as differences in prey foraging rates in the presence of a predator threat, may help reveal the indirect effect of condition on predation risk (Lima \& Dill 1990, Steele \& Forrester 2002).

Condition can have a direct impact on the selective mortality of reef fish recruits (Booth \& Hixon 1999, Searcy \& Sponaugle 2001, Booth \& Beretta 2004, Hoey \& McCormick 2004); however, little is known about the actual mechanisms leading to enhanced survival of higher condition fishes. In both Barbados and the Florida Keys, survivors from multiple cohorts of Thalassoma bifasciatum most frequently had higher condi- tion relative to that of the initial settlers (Searcy \& Sponaugle 2001, Grorud-Colvert 2006). The present study was designed to identify potential behavioral mechanisms by which physiological condition may affect postsettlement survival of reef fishes. Using Thalassoma bifasciatum recruits with natural and experimentally produced variation in condition, we combined otolith analysis of early life history traits and behavioral observations to investigate the potential links between these traits, physiological condition, and the behavior of reef fish recruits.

\section{MATERIALS AND METHODS}

Natural variability in condition: influence on swimming performance. To examine variability in condition of coral reef fish recruits, newly settled Thalassoma bifasciatum from multiple cohorts were collected from reefs in the upper Florida Keys. T. bifasciatum is one of the most abundant coral reef fishes in the Florida Keys and is found at high densities throughout the Caribbean. Larvae settle to the reef after a variable planktonic duration of 38 to 94 d (Victor 1982, Sponaugle \& Cowen 1997), then bury into the sand and rubble on the periphery of Florida Keys reefs during third quarter and new moon periods (Sponaugle et al. 2006). New settlers remain buried for a period of 3 to $5 \mathrm{~d}$, during which they undergo metamorphosis, emerging onto the reef as fully pigmented juveniles (Victor 1982). Remaining near the reef, T. bifasciatum recruits join aggregations of similarly sized juveniles, often of multiple species, as they age (Sponaugle \& Cowen 1997). From September to December 2003, individuals were collected from the reef 1 to $3 \mathrm{~d}$ post-emergence by teams of divers using SCUBA techniques and the anesthetic quinaldine (Sigma). Fish were transported to the University of Miami's aquarium facility and kept in $110 \mathrm{l}$ tanks filled with unfiltered seawater before experimentation.

Swimming capability: To investigate whether fishes of different condition levels exhibit behaviors that may make them more or less susceptible to predation, we examined the swimming capability of newly settled recruits encompassing a natural range of condition levels, evaluated using otolith-derived traits. Swimming trials were conducted immediately (within $4 \mathrm{~d}$ of capture) to ensure a sufficient sample size. Recruits swam in a 3-chambered semi-recirculating flume (1 recruit per chamber, modified after Jenkins \& Welsford 2002) in which water was pumped from a reservoir into the chambers (Jacuzzi pump, Stingray JP1, $0.75 \mathrm{hp}$ ). Although water recirculated through the flume, temperatures were held at $\sim 26^{\circ} \mathrm{C}$ (comparable with reef water temperatures at the time of capture), by the con- 
stant input of fresh seawater. At the upstream end of each chamber, a ball valve regulated the current speed and a bundle of plastic drinking straws straightened the flow, effectively reducing turbulence. Flow was quantified by videotaping neutrally buoyant particles released at each subsequent speed increase using a black and white high-resolution camera with a wideangle varifocal zoom lens (Super Circuits, PC-23C). Particle speed was determined by digitizing the video using Pinnacle Studio software (Pinnacle Systems, v. 8.8.15.0) and calculating the speed using RedLake software (MotionScope PCI, v. 2.3). A single fish was placed in each of the 3 chambers by removing the rubber connector at the excurrent opening of the flume. Additional water was then added to fill the flume and recruits were given a 15 min acclimation period without current. Any recruit not swimming or swimming erratically was removed and excluded from the analysis $(n=4)$. After the acclimation period, flow was increased by approximately $5 \mathrm{~cm} \mathrm{~s}^{-1}$ every $5 \mathrm{~min}$, when exact calculations were made for each chamber. For each recruit, critical swimming speed $\left(U_{\text {crit }}\right)$ was calculated following Brett (1964): $U_{\text {crit }}=U+\left(t / t_{i} \times U_{i}\right)$, where $U$ is the penultimate speed, $t$ is the time spent swimming at ultimate speed, $t_{i}$ is the time increment, and $U_{i}$ is the speed increment. Recruits were divided into 3 categories based on their swimming capability $\left(U_{\text {crit }}\right)$, allowing comparison of traits associated with swimming capability by group using ANOVA techniques (Zar 1999). When the assumption of normality was not met, we used a non-parametric Kruskal-Wallis or Mann-Whitney test (Zar 1999). At the end of each swimming trial, recruits were removed and euthanized using cold shock, measured for standard length (SL), their heads separated and preserved in $95 \%$ ethanol for otolith analysis, and body tissue frozen in a $-20^{\circ} \mathrm{C}$ freezer for condition analysis.

Otolith analysis: Like many fishes, Thalassoma bifasciatum possesses a daily record of age and transitional events (i.e. settlement) in its otoliths, or ear stones (Victor 1982, Sponaugle \& Cowen 1997), providing a historical record of growth and condition during different life stages. Age and length of early life history stages were obtained using otolith growth increments. A strong relationship between $T$. bifasciatum standard length and otolith size allows the use of otolith size as a measure of relative size-at-age (Victor 1982, Sponaugle \& Cowen 1997, Searcy \& Sponaugle 2001). Otolith increment widths provide a relative measure of larval and juvenile growth rates, as well as width of the band deposited during metamorphosis (material deposited after settlement and before emergence; wider bands are thought to indicate higher condition, Searcy \& Sponaugle 2001). We followed a standard protocol to prepare otoliths for analysis (Sponaugle \& Pinkard
2004). Both pairs of lapillar and sagittal otoliths were removed from $T$. bifasciatum, although only the sagittae were examined for the purposes of this study. Otoliths were cleaned and stored in medium viscosity immersion oil for 15 to $30 \mathrm{~d}$ to facilitate clearing (i.e. to make otolith features more visible). Afterwards they were examined with a Leica microscope equipped with a polarized filter at $400 \times$ oil-immersion magnification. The image was captured and transferred to a computer using a Dage MTI video camera and frame grabber and sharpened and analyzed by means of Image Pro-Plus 4.5 image analysis software (Media Cybernetics). Otolith increments were enumerated along the longest axis from the core to the edge of the otolith and were identified as larval (increments before the settlement mark), metamorphic (increments between the settlement and emergence marks), or juvenile (increments after the emergence mark). The position of each otolith increment was digitized to provide estimates of relative size-at-age (distance from core to each increment) and growth rates during particular periods (widths between selected increments). All otoliths were read blind a minimum of 2 times by a single reader. Any otolith that did not show $\leq 5 \%$ agreement was re-read a third time, after which the otolith was discarded if the disagreement was still high.

Fish otoliths were examined after the swimming trial to identify differences in early life history traits among individuals with varying swimming capabilities. Otoliths were examined for larval growth (mean larval increment width for each day of larval life), pelagic larval duration (PLD), size-at-settlement, width of the metamorphic band, and mean early juvenile growth (mean juvenile increment width during the first $4 \mathrm{~d}$ on the reef). Comparison of larval growth trajectories by swimming group was performed using multivariate analysis of variance (MANOVA) techniques (Chambers \& Miller 1995, Meekan \& Fortier 1996). Other mean early life history traits were compared by swimming group using ANOVA or non-parametric techniques (Zar 1999) to identify traits associated with swimming capability.

Experimental variability in condition: influence on swimming, foraging, and predator evasion. To further examine the impact of condition on swimming as well as predator evasion, 2 condition treatments of recruits were established. New recruits of Thalassoma bifasciatum were collected 1 to $3 \mathrm{~d}$ post-emergence from the upper Florida Keys and transported to the University of Miami's aquarium facility, where they were randomly assigned to one of two 1101 tanks with circulating unfiltered seawater. Equal numbers of recruits were haphazardly placed in each tank to approximate similar length and age distributions between treat- 
ments. Before the collection of recruits, tanks were allowed to establish an epiphyte algal community with associated micro-organisms as a base food source. Recruits placed in the low (LO) condition treatment received no additional food. Individuals subjected to the high (HI) condition treatment were given an additional food source of thawed and suspended adult Artemia, fed daily ad libitum. Recruits were maintained in each treatment for a period of $7 \mathrm{~d}$, allowing time for food resources to translate into differences in growth and condition. At the end of this period, 60 recruits (30 from each treatment) were randomly chosen, euthanized, measured for SL, and preserved to quantify condition levels. Heads of the sacrificed individuals were removed for otolith analyses to compare the physiological condition of both $\mathrm{HI}$ and LO recruits using growth-based attributes. Juvenile growth over the $7 \mathrm{~d}$ condition treatment was compared by investigating differences in mean juvenile increment width for the first and second $3 \mathrm{~d}$ periods of the treatment using a Mann-Whitney test for non-normally distributed data (Zar 1999). Bodies were dried in a $60^{\circ} \mathrm{C}$ oven to calculate Fulton's condition factor $(K=$ [dry weight (g)] [standard length $(\mathrm{mm})]^{-3}$ ), and differences between the HI and LO condition treatments were then evaluated using Student's $t$-test (Zar 1999).

Swimming capability: We examined the swimming capability of $\mathrm{HI}$ and LO condition recruits immediately after the condition treatment. A sample of 30 recruits from each treatment was randomly chosen and subjected to swimming trials in the flumes following the same protocol used for newly caught recruits. Critical swimming speed was compared between the HI and LO condition recruits. We also compared critical swimming speed of the previously examined newly caught individuals with the $\mathrm{HI}$ and LO condition recruits. We examined similarity among the 3 groups using a Kruskal-Wallis test for non-normally distributed data (Zar 1999).

Foraging behavior: A second set of recruits from the condition treatment was used to investigate the effect of condition on foraging behavior in the presence and absence of a predation threat. A behavioral trial was conducted immediately after fish were exposed to the condition treatment (i.e. no fish were $>11$ d post-emergence). During each trial, randomly selected recruits of either HI or LO condition were assigned to one of 4 tanks. Tanks were $230 \mathrm{l}$ and each contained a single piece of coral rock in the center for shelter. Two tanks received $10 \mathrm{HI}$ condition recruits each and 2 tanks received $10 \mathrm{LO}$ condition recruits each for a total of 40 recruits per trial. Recruits were left to acclimate in the tank overnight, and at the beginning of the trial the next day $2 \mathrm{ml}$ of thawed Artemia was introduced to one corner of each tank. During the trial, 2 tanks of recruits, one of $\mathrm{HI}$ condition and one of LO condition fish, were exposed to the threat of predation. The predator threat was simulated by a wooden fish model, rapidly dunked into the experimental tank for a period of 15 to $20 \mathrm{~s}$ from behind a light-colored blind. Trials were videotaped using a monochrome digital quad processor with 2 black and white micro-video cameras (Super Circuits, PC-60XS) per tank (above and to the side), to enable quantification of foraging behavior during the recorded session. Recruit behavior was recorded for $1 \mathrm{~h}$ before the attack and $1 \mathrm{~h}$ after. This protocol was then repeated with a new set of treatment fish from a second cohort. In total, there were 2 tanks of $\mathrm{HI}$ and 2 tanks of LO condition fish threatened by a predator and 2 tanks of $\mathrm{HI}$ and 2 tanks of LO condition fish not exposed to a predator threat (80 individuals tested, $40 \mathrm{HI}$ and $40 \mathrm{LO}$ condition).

After the trials, video footage was digitized in $5 \mathrm{~min}$ intervals at a frame rate of $15 \mathrm{~s}^{-1}$ and a temporal resolution of $0.071 \mathrm{~s}$ using the digitizing software Pinnacle Studio (Pinnacle Systems, v. 8.8.15.0) and viewed using RedLake software (MotionScope PCI, v. 2.3). The 5 min time periods were recorded for each condition and predator treatment during and immediately after the predator threat. The number of recruits sheltered per time interval was recorded by observing the number of fish hiding under or in crevices of the shelter at each $30 \mathrm{~s}$ of the $5 \mathrm{~min}$ observation period. To ensure accuracy and avoid replication, these data were used to obtain a single mean for the number of recruits sheltered in each of the 2 trials. Similarly, consumption rates per recruit per time interval were quantified by observing the number of fish consuming Artemia at each $30 \mathrm{~s}$ of the $5 \mathrm{~min}$ observation period and obtaining a single mean. The number of recruits that remained sheltered or were consuming food was then compared between condition level (HI or LO) and predation threat (present or absent) using a 2-way ANOVA (Zar 1999). Finally, for those trials where recruits were threatened by the predator model, evasion speed was measured using the distance and time each fish traveled to evade the predator model. Evasion speeds were compared for HI and LO recruits using Student's $t$-test.

\section{RESULTS}

\section{Natural variation in condition and swimming capa- bility of new recruits}

Newly settled Thalassoma bifasciatum recruits showed a range in swimming capability (1.6 to $28.7 \mathrm{~cm}$ $\mathrm{s}^{-1}, \mathrm{n}=115$, mean: $9.4 \pm 0.8[\mathrm{SE}] \mathrm{cm} \mathrm{s}^{-1}$ ). There was no relationship between SL (range: 10.2 to $15.2 \mathrm{~mm}$ ) and critical swimming speed $\left(\mathrm{R}^{2}=0.027, \mathrm{p}=0.210\right)$; there- 
Table 1. Thalassoma bifasciatum. Mean values of otolith-based early life history traits and statistical test results for newly settled recruits of 3 swimming groups determined by critical swimming speed $\left(\mathrm{cm} \mathrm{s}^{-1}\right)$. LG: larval growth measured as the mean larval otolith increment width over the entire pelagic larval duration; PLD: pelagic larval duration; SS: otolith size-at-settlement or radius at the settlement mark; BW: width of the otolith metamorphic band; JG: juvenile growth measured as the mean otolith increment width for the combined first $4 \mathrm{~d}$ on the reef. MAN: MANOVA; K-W: Kruskal-Wallis. All post-hoc analyses were performed using a Mann-Whitney test

\begin{tabular}{|lcccccccc|}
\hline \multirow{2}{*}{$\begin{array}{l}\text { Early life } \\
\text { history trait }\end{array}$} & \multicolumn{9}{c}{ Critical swimming speed } & Test & Test statistic & df & p & Post-hoc \\
\hline LG $(\mu \mathrm{m})$ & $0-10$ & $10-20$ & $20-30$ & & & & & \\
PLD $(\mathrm{d})$ & 4.45 & 4.46 & 4.89 & MAN & $\lambda=1.98$ & 54 & 0.048 & $20-30<0-10,10-20$ \\
SS $(\mu \mathrm{m})$ & 44 & 42 & 35 & K-W & $H=7.50$ & 2 & 0.024 & $20-30<0-10$ \\
BW $(\mu \mathrm{m})$ & 201.52 & 195.74 & 179.84 & K-W & $H=6.02$ & 2 & 0.049 & 0.204 \\
JG $(\mu \mathrm{m})$ & 19.49 & 20.20 & 22.85 & K-W & $H=3.18$ & 2 & \\
& 5.93 & 6.10 & 6.24 & K-W & $H=0.88$ & 2 & 0.645 & \\
\hline
\end{tabular}

fore, length-based adjustments were not required for the swimming data (Stobutzki \& Bellwood 1994, Bellwood \& Fisher 2001, Sogard \& Olla 2002). Sub-samples of fish that swam over a period of $4 \mathrm{~d}$ showed no difference in swimming capability by day (Kruskal-Wallis: $H$ $=6.142, \mathrm{df}=3, \mathrm{p}=0.105$ ); thus, all data were pooled to obtain an adequate sample size. Fish were arbitrarily separated into 3 groups based on different critical swimming speed bins of $10 \mathrm{~cm} \mathrm{~s}^{-1}$ (i.e. $0-10,10-20$, and $20-30 \mathrm{~cm} \mathrm{~s}^{-1}$ ). To compare recruits from the same cohort, only fish that settled during a $7 \mathrm{~d}$ window were used for the otolith analysis (i.e. 115 fish swam, but the otoliths of only 61 individuals belonging to the appropriate cohorts were analyzed). Early life history traits of these groups revealed significant differences in larval growth trajectories, PLD, and size-at-settlement (Table 1, MANOVA interaction term was not significant: $F=0.84, \mathrm{p}=0.619)$ such that fish with better swimming capabilities were those that grew faster as

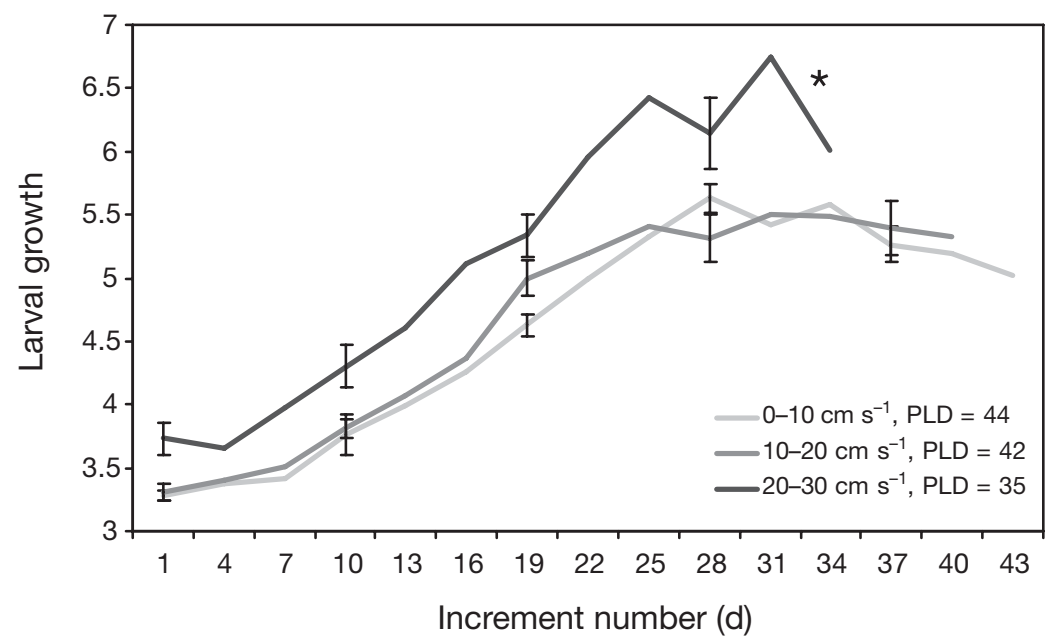

Fig. 1. Thalassoma bifasciatum. Mean $( \pm \mathrm{SE})$ larval growth (mean otolith increment width, $\mu \mathrm{m}$ ) by day post-hatch for 3 groups of newly settled recruits determined by critical swimming speed $\left(\mathrm{cm} \mathrm{s}^{-1}\right)$. Larval growth trajectories are plotted to the mean pelagic larval duration (PLD) for each group. ${ }^{*} \mathrm{p}<0.05$ larvae (Fig. 1), had shorter PLDs, and were smaller-atsettlement (Fig. 2), although these recruits were a relatively small proportion of the total sample (6 out of 61 fish). The otolith metamorphic band tended to be wider in better swimmers but this was not significant (Table 1, Fig. 2). Early juvenile growth did not differ among the groups with different swimming speeds (Table 1, Fig. 2).

\section{Experimental variation in recruit condition}

By the end of the condition treatment, HI condition recruits had significantly faster juvenile otolith growth than LO condition recruits (beginning: Mann-Whitney, $U=3896.5, \mathrm{p}=0.144$; end: Mann-Whitney, $U=4979.5$, $\mathrm{p}=0.002$; Fig. 3). Similarly, HI condition recruits had higher Fulton's condition indices than LO condition recruits at time of sacrifice (means: $2.11 \times 10^{-6}$ and $1.43 \times 10^{-6} \mathrm{~g} \mathrm{~mm}^{-3}$, respectively; $t$ test, $t=5.132$, df $=94, \mathrm{p}<0.001$ ). There was no difference in standard length between the HI and LO recruits at the end of the condition treatment (means: 13.36 and $13.01 \mathrm{~mm}$, respectively; $t$-test, $t=$ 0.848, df $=94, p=0.398$ ).

A total of 56 experimental recruits (27 HI and 29 LO) swam in the flume. Swimming capability of the HI condition fish was similar to that of the newly caught recruits and both swam significantly faster than the LO condition fish (Kruskal-Wallis, $H=23.866, \mathrm{p}<$ 0.001; HI, NEW > LO, p < 0.001).

During the first $5 \mathrm{~min}$ immediately after the predator threat, there were significant differences in the number of recruits sheltered 

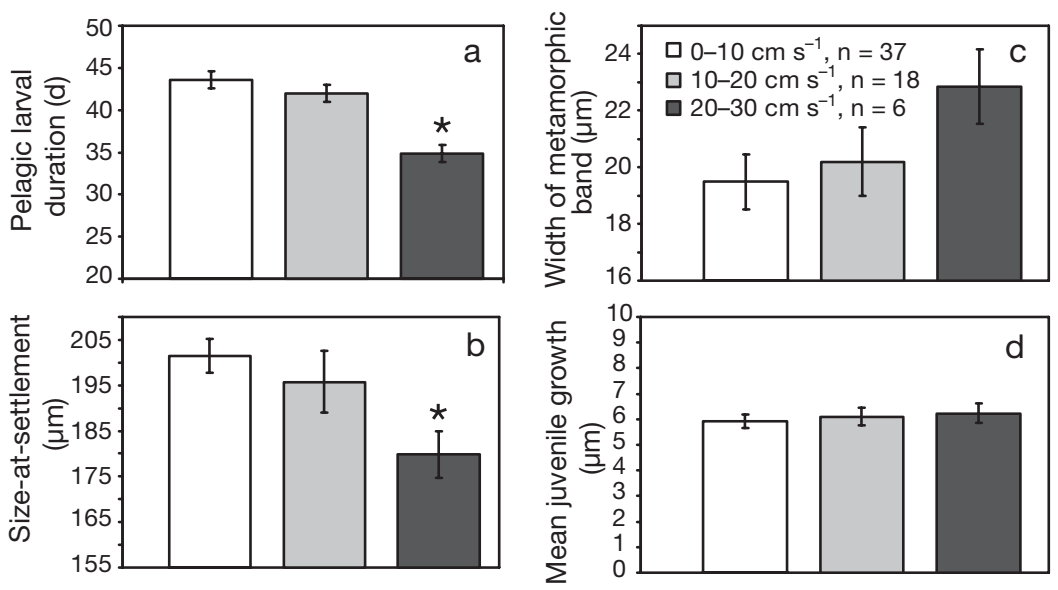

Fig. 2. Thalassoma bifasciatum. Mean $( \pm \mathrm{SE})(\mathrm{a})$ pelagic larval duration, (b) sizeat-settlement, (c) width of the otolith metamorphic band, and (d) juvenile growth during the first $4 \mathrm{~d}$ on the reef for 3 groups of newly caught recruits determined by critical swimming speed $\left(\mathrm{cm} \mathrm{s}^{-1}\right)$. ${ }^{*}$ Kruskal-Wallis test, $\mathrm{p}<0.05$

Molony 1992, Stobutzki 1997, Booth \& Hixon 1999, Green \& McCormick 1999, Searcy \& Sponaugle 2001, Booth \& Beretta 2004). Condition influences post-settlement survival of Thalassoma bifasciatum (Searcy \& Sponaugle 2001, Grorud-Colvert 2006), and the present study reveals that several key behaviors (swimming capability and foraging behavior) may underlie this relationship.

\section{Natural variability in life history traits and condition}

Newly settled recruits in this study exhibited a natural within-cohort range of early life history traits associated with condition. Multiple factors

by both condition level and predator threat presence or absence (Table 2, Fig. 4a). HI condition fish spent significantly more time sheltered than LO condition fish. Greater numbers of both $\mathrm{HI}$ and LO condition fish were sheltered when a predator threat was present than in the absence of a threat (Table 2, Fig. 4a). Similarly, there were significant differences in consumption by both condition level and predator threat presence or absence (Table 2, Fig. 4b). HI condition fish consumed significantly less than LO condition fish when a predator threat was present and absent (Fig. 4b). In addition, consumption of both HI and LO condition recruits was lower when they were exposed to the threat of predation than in the absence of a predator threat. When exposed to a predator threat, $\mathrm{HI}$ condition fish evaded the predator faster than LO condition fish (logtransformed data; means: 8.73 and $3.88 \mathrm{~cm} \mathrm{~s}^{-1}$, respectively; $t$-test, $t=$ 3.077, $\mathrm{p}=0.004)$.

\section{DISCUSSION}

Our results indicate that early life history traits and associated condition levels of newly settled reef fishes are variable and that individuals of higher condition usually perform better. These data identify new links among condition, otolith-derived early life history traits, and behavior, in addition to corroborating previous work identifying physiological and behavioral measures of condition (e.g. McCormick \&

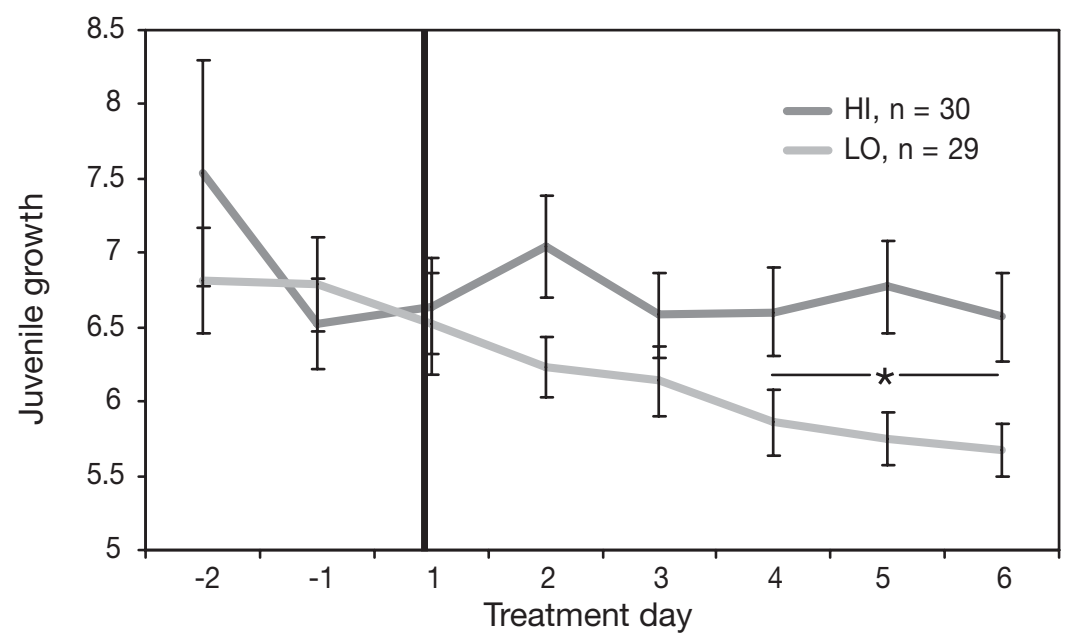

Fig. 3. Thalassoma bifasciatum. Mean $( \pm \mathrm{SE}$ ) juvenile growth (otolith increment width, $\mu \mathrm{m}$ ) of recruits from feeding treatments by back-calculated date. Vertical bar: initiation of feeding treatments. HI: recruits fed ad libitum; LO: deprived recruits. *Mann-Whitney test, $\mathrm{p}<0.01$ 
Table 2. Thalassoma bifasciatum. Statistical 2-way ANOVA for the number of recruits sheltering and consuming food in experimental trials comparing high (HI) and low (LO) condition recruits established during feeding treatments. Results are for behavior of threatened recruits and nonthreatened recruits from $\mathrm{HI}$ and LO condition treatments. Degree of freedom was 1 for all factors

\begin{tabular}{|llrrr|}
\hline & Factor & $F$ & df & p \\
\hline \multirow{5}{*}{ Sheltering } & Condition & 259.314 & 1 & $<0.001$ \\
& Predator threat & 216.176 & 1 & $<0.001$ \\
& Interaction & 0.020 & 1 & 0.895 \\
Consuming & Condition & 45.023 & 1 & 0.003 \\
& Predator threat & 113.953 & 1 & $<0.001$ \\
& Interaction & 0.837 & 1 & 0.412 \\
\hline
\end{tabular}

be larger and heavier, with greater concentrations of lipids, carbohydrates and proteins, shorter PLDs, larger size-at-metamorphosis, greater capacity for energy storage, and increased musculature development compared with larvae fed at lower levels (McCormick \& Molony 1992, Green \& McCormick 1999). Finally, regardless of abiotic and biotic factors, inherent genotypic responses or parental physiology, including oil globule volume, larval size, growth rates, and time to starvation (Berkeley et al. 2004, Green \& McCormick 2005) can also lead to beneficial characteristics during early life.

Variability in life histories leads to an unequal probability of survival for newly settled fishes. Fishes with better swimming capabilities were those with faster larval growth and shorter PLDs. Selection for faster growing individuals is predicted by the growth-mortality hypothesis, and this selective mortality for slower growing individuals also occurs in other systems and species (e.g. Meekan \& Fortier 1996, Hare \& Cowen 1997, Searcy \& Sponaugle 2001, Shima \& Findlay 2002, Vigliola \& Meekan 2002, McCormick \& Hoey 2004, Sponaugle et al. 2006). For Thalassoma bifasciatum cohorts from the Florida Keys, however, growth-based selective mortality was not evident, which is likely the result of temperature-induced similarities in larval growth within cohorts (Grorud-Colvert 2006). Instead, higher variation in condition within cohorts led to more frequent condition-based selective mortality.

The best swimmers were smaller at settlement, but experimental recruits were similar in size after the first few days as juveniles on the reef as well as at the time of our swimming trials. Smaller settlement size is associated with faster larval growth and a shorter PLD as fish that grow faster settle more rapidly and at smaller sizes than recruits with longer PLDs (Sponaugle et al. 2006). Smaller size-at-settlement can provide a survival advantage since larger larvae are often more conspicuous, leading to increased en- counter rates and probability of being perceived by predators at time of settlement (Pepin et al. 1992). However, size alone does not appear to influence survival of Thalassoma bifasciatum (Searcy \& Sponaugle 2001, Grorud-Colvert 2006). In fact, size differences at settlement became obscured after a few days spent as juveniles on the reef: fast-growing, HI condition settlers continued to grow fast and caught up to those individuals that were larger at settlement and of lower condition. Although size is not always a measure of condition, in this study, recruits that were smaller at settlement grew faster as larvae (generally associated with high condition-at-settlement, Searcy \& Sponaugle 2001) and showed a tendency toward higher condition at settlement (wider otolith metamorphic bands).

\section{Behavioral correlates of condition}

Thalassoma bifasciatum recruits with faster larval growth, shorter PLDs, and smaller size-at-settlement were also more capable swimmers. Mean critical swimming speeds of recruits in our study $\left(10.6 \mathrm{~cm} \mathrm{~s}^{-1}\right)$ were slower than those of both laboratory-reared and wild-caught late-stage larval species (range of means: 18.6 to $45.3 \mathrm{~cm} \mathrm{~s}^{-1}$; Fisher et al. 2000, Fisher \& Wilson 2004) as well as those of early post-settlement juve-

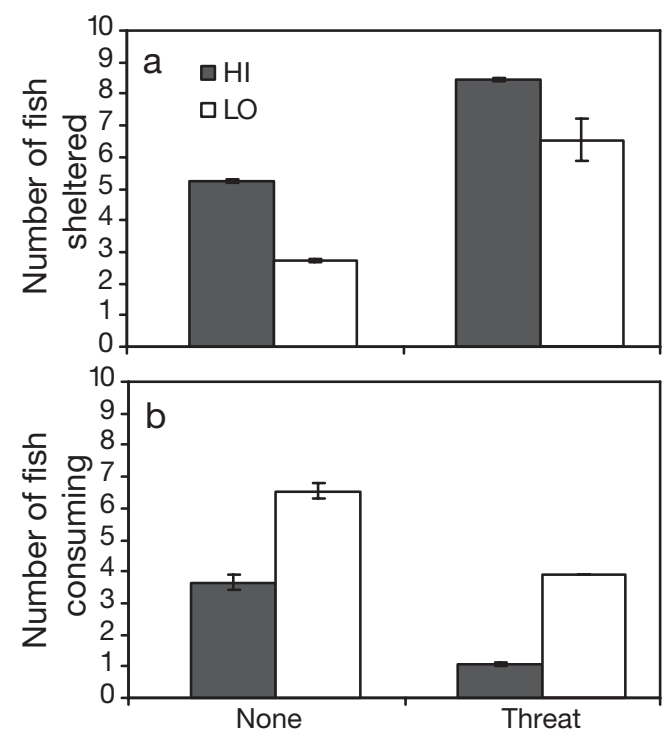

Fig. 4. Thalassoma bifasciatum. Mean $( \pm \mathrm{SE})$ number of high (HI) and low (LO) condition recruits that were (a) sheltered and (b) consuming food in experimental trials. Results are for behavior immediately after a predator threat was introduced to threatened recruits (Threat) and at the same time for nonthreatened recruits (None) from the HI and LO condition treatments. $\mathrm{SE}=0$ for $\mathrm{LO}$ condition recruits that were threatened while consuming food 
niles (26.3 $\mathrm{cm} \mathrm{s}^{-1}$, Stobutzki \& Bellwood 1994). Relative swimming ability tends to decrease with increasing body length (Bellwood \& Fisher 2001), and newly settled recruits of 3 pomocentrid species exhibited slower critical swimming speeds than larval conspecifics (Stobutzki \& Bellwood 1994). This ontogenetic decrease in swimming capability as well as substantial taxonomic differences for labrids most likely explains our lower values. Nevertheless, our recruits showed a wide range of swimming capabilities that corresponded to particular early life history traits. Consistent with this, goatfish larvae fed at higher levels had increased levels of lipids, carbohydrates and proteins, shorter PLDs, and an increase in muscle development, which are all hypothesized to increase swimming capability (McCormick \& Molony 1992).

Swimming is an energetically costly activity (Stobutzki 1997), and the ability to maintain position in a current is an important physiological benchmark. Individuals that can swim at increasing current speeds indicate possession of greater energetic reserves that are more readily available for use. When we used feeding treatments to produce recruits of 2 condition levels, HI condition, faster-growing Thalassoma bifasciatum were more capable swimmers. Similarly, when recruits were threatened by a simulated predator attack, HI condition recruits had faster evasion speeds than LO condition recruits. Other studies have also demonstrated a direct link between condition of fishes and swimming performance, responsiveness to predators, or competitive dominance (Chick \& Van den Avyle 2000, Sogard \& Olla 2002, Booth \& Beretta 2004). When high and low condition damselfish Stegastes partitus were exposed to a predator, more predator strikes were directed at the low condition fish and all of these were consumed, most likely due to the erratic behavior and slower evasion the authors anecdotally reported (Booth \& Beretta 2004). Critical swimming speed, evasion speed, and other evasive behaviors can influence the outcome of a predator encounter by predicting how quickly a fish can respond as well as how fast and how long a recruit can outswim a predator. Obviously, the outcome of this interaction has direct relevance for the survival of the recruit.

Additional routine behaviors, such as those associated with foraging, can also influence survival by affecting the number of times a recruit encounters a predator. In both replicate trials, HI condition recruits sheltered more and consumed significantly less food than LO condition recruits immediately after a predator threat. An increase in foraging rate and decrease in time spent sheltered, or an increase in food consumption rates in an unprotected location, increases the risk of predation (Godin \& Sproul 1988, Lima \& Dill 1990, Sih 1998). Many species reduce their rate of foraging in the presence of a predator (Holbrook \& Schmitt 1988, Lima \& Dill 1990, Pressier et al. 2005), and fishes of higher condition may better tolerate a decrease in foraging as they rely on their increased energy stores to survive the period of reduced food consumption while taking shelter. Similar results were found for fooddeprived juvenile walleye pollock Theragra chalcogramma, which spent more time in the vicinity of food than the fully fed controls when exposed to a predator threat (Sogard \& Olla 2002). Other routine behaviors affected by predator presence can include time to resume feeding after a threat (Godin \& Sproul 1988) and choice of habitat in which to forage (Holbrook \& Schmitt 1988).

On the reef, a change in routine behaviors may result in mortality of fishes of lower condition, but we could not evaluate this since our trials did not include a live predator. Additionally, the sublethal effects of a predator may have long-term consequences, leading to decreased individual growth rates (Steele \& Forrester 2002) or modification of competitive interactions and habitat choice (Lima \& Dill 1990). A recent metaanalysis by Pressier et al. (2005) used 166 studies from 49 publications to illustrate that the mere presence of a predator has a similar or greater effect on prey population density than predation itself. In addition, this effect was more pronounced in aquatic systems than terrestrial ones and was greater in marine compared with freshwater systems. Our results illustrate a direct mechanism by which the long-term fitness of reef fishes might be reduced. Although HI condition fish were able to spend less time foraging and more time sheltered and away from a predator, eventually a trade-off will exist for these individuals since periods of lower consumption cannot be indefinite. More work is needed to understand the long-term dynamics of newly settled fishes foraging under the threat of predation and the countervailing pressures influencing their survival.

\section{Implications for post-settlement survival}

Our results show that success during life history transitions can be linked to both early life history traits and other measures of condition. Specific life history traits associated with condition, such as larval growth, PLD, and size-at-settlement, can lead to an advantage for juveniles on the reef, in this case through increased swimming ability of certain individuals. Although these recruits comprised only $10 \%$ of the sample population, this is not an inconsequential proportion. Fuiman \& Cowan (2003) found that exceptional larval red drum Sciaenops ocellatus that performed well or consistently in multiple skills comprised only 1 to $2 \%$ 
of their sample. The authors suggested that these numbers were not trivial when multiplied over the reproductive lifetime of a female. Other studies have also found that survivors were a small proportion of the pre-selection group (Meekan \& Fortier 1996, Hare \& Cowen 1997).

Fishes that engage in behaviors designed to minimize predation and starvation will have an advantage over those that exhibit lower capabilities or greater risk-taking. Results of this study identify a direct link between condition (quantified using otolith growth history), standardized weight, and juvenile behavior. HI condition recruits exhibited greater swimming capabilities and faster predator evasion speeds as well as decreased foraging and consumption in the presence of a predator threat. High variability in condition led to frequent condition-based selective mortality in cohorts of Thalassoma bifasciatum over multiple years, seasons, and locations (Searcy \& Sponaugle 2001, GrorudColvert 2006). Similarly, newly settled damselfish with both natural and experimentally produced variability in condition also demonstrated selective loss of low condition individuals (Booth \& Hixon 1999, Booth \& Beretta 2004, Hoey \& McCormick 2004). Condition may also alter the strength of density-dependent mortality if differential quality of settling larvae or new recruits leads to a decoupling between settlement and mortality rates (Wilson \& Osenberg 2002).

Selective loss of lower condition members from the population leads to higher condition survivors at subsequent life history stages. Recent work has identified the benefits that larger and older females can impart to their offspring, including a greater oil globule volume, larger hatch size, faster larval growth, greater resistance to starvation, and increased survival (Berkeley et al. 2004, Green \& McCormick 2005, Trippel et al. 2005). Our study links early life history traits, condition levels, and specific behaviors such as swimming and foraging for newly settled labrid recruits. Although these results add to the growing body of knowledge concerning the importance of condition-related factors for survival of early life stages of fishes, how these events in early life are translated to subsequent stages is largely unknown.

Acknowledgements. We thank M. Paddack, K. Denit, D. Pinkard, D. Richardson, S. Cappell, and C. Paris for help with collecting recruits from the field. Help with physiological measurements was provided by L. Fieber and M. Grosell, who also supplied use of their laboratory facilities. C. Guigand, K. Huebert, J. Serafy, T. Capo, and R. Fisher provided advice and assistance with construction of the flume. C. Guigand also helped with the design and implementation of the video system, and the protocol for the foraging trials was improved by suggestions from S. Sogard. This manuscript benefited from the comments of R. Cowen, S. Sogard, J. McManus, J. Bohnsack, and 5 anonymous reviewers.

\section{LITERATURE CITED}

Anderson JT (1988) A review of size dependent survival during pre-recruitment stages of fishes in relation to recruitment. J Northwest Atl Fish Sci 8:55-66

Bailey KM, Houde ED (1989) Predation on eggs and larvae of marine fishes and the recruitment problem. Adv Mar Biol 25:1-83

Bellwood DR, Fisher R (2001) Relative swimming speeds in reef fish larvae. Mar Ecol Prog Ser 211:299-303

Bergenius MAJ, Meekan MG, Robertson DR, McCormick MI (2002) Larval growth predicts the recruitment success of a coral reef fish. Oecologia 131:521-525

Berkeley SA, Chapman C, Sogard SM (2004) Maternal age as a determinant of larval growth and survival in a marine fish, Sebastes melanops. Ecology 85:1258-1264

Booth DJ, Beretta GA (2004) Influence of recruit condition on food competition and predation risk in a coral reef fish. Oecologia 140:289-294

Booth DJ, Hixon MA (1999) Food ration and condition affect early survival of the coral reef damselfish, Stegastes partitus. Oecologia 121:364-368

Brett JR (1964) The respiratory metabolism and swimming performance of young sockeye salmon. J Fish Res Board Can 21:1183-1226

Carr MH, Hixon MA (1995) Predation effects on early postsettlement survivorship of coral reef fishes. Mar Ecol Prog Ser 124:31-42

Chambers RC, Miller TJ (1995) Evaluating fish growth by means of otolith increment analysis: special properties of individual-level longitudinal data. In: Secor DH, Dean JM, Campana SE (eds) Recent developments in fish otolith research. University of South Carolina Press, Columbia, $\mathrm{SC}, \mathrm{p} 155-175$

Chick JH, Van den Avyle MJ (2000) Effects of feeding ration on larval swimming speed and responsiveness to predator attacks: implications for cohort survival. Can J Fish Aquat Sci 57:106-115

Fisher R, Wilson SK (2004) Maximum sustainable swimming speeds of late-stage larvae of nine species of reef fishes. J Exp Mar Biol Ecol 312:171-186

Fisher R, Bellwood DR, Job SD (2000) Development of swimming abilities in reef fish larvae. Mar Ecol Prog Ser 202: 163-173

Fuiman LA, Cowan JH (2003) Behavior and recruitment success in fish larvae: repeatability and covariation of survival skills. Ecology 84:53-67

Godin JGJ, Sproul CD (1988) Risk-taking in parasitized sticklebacks under threat of predation-effects of energetic need and food availability. Can J Zool 66:2360-2367

Green BS, Fisher R (2004) Temperature influences swimming speed, growth and larval duration in coral reef fish larvae. J Exp Mar Biol Ecol 299:115-132

Green BS, McCormick MI (1999) Influence of larval feeding history on the body condition of Amphiprion melanopus. J Fish Biol 55:1273-1289

Green BS, McCormick MI (2005) Maternal and paternal effects determine size, growth and performance in larvae of a tropical reef fish. Mar Ecol Prog Ser 289:263-272

Grorud-Colvert K (2006) Predation in marine reserves and its impact on the survival and early life histories of newlysettled reef fishes. PhD dissertation, University of Miami, Coral Gables, FL

Hare JA, Cowen RK (1997) Size, growth, development, and survival of the planktonic larvae of Pomatomus saltatrix (Pisces: Pomatomidae). Ecology 78:2415-2431

Hixon MA (1991) Predation as a process structuring coral reef 
communities. In: Sale PF (ed) The ecology of fishes on coral reefs. Academic Press, San Diego, CA, p 475-507

Hoey AS, McCormick MI (2004) Selective predation for low body condition at the larval-juvenile transition of a coral reef fish. Oecologia 139:23-29

Holbrook SJ, Schmitt RJ (1988) Effects of predation risk on foraging behavior-mechanisms altering patch choice. J Exp Mar Biol Ecol 121:151-163

Houde ED (1987) Fish early life dynamics and recruitment variability. Am Fish Soc Symp 2:17-29

Houde ED (1989) Comparative growth, mortality, and energetics of marine fish larvae - temperature and implied latitudinal effects. Fish Bull 87:471-495

Jenkins GP, Welsford DC (2002) The swimming abilities of recently settled post-larvae of Sillaginodes punctata. J Fish Biol 60:1043-1050

Lima SL, Dill LM (1990) Behavioral decisions made under the risk of predation-a review and prospectus. Can J Zool 68:619-640

McCormick MI, Hoey AS (2004) Larval growth history determines juvenile growth and survival in a tropical marine fish. Oikos 106:225-242

McCormick MI, Molony BW (1992) Effects of feeding history on the growth characteristics of a reef fish at settlement. Mar Biol 114:165-173

McCormick MI, Molony BW (1993) Quality of the reef fish Upeneus tragula (Mullidae) at settlement: Is size a good indicator of condition? Mar Ecol Prog Ser 98:45-54

Meekan MG, Fortier L (1996) Selection for fast growth during the larval life of Atlantic cod Gadus morhua on the Scotian Shelf. Mar Ecol Prog Ser 137:25-37

Meekan MG, Carleton JH, McKinnon AD, Flynn K, Furnas M (2003) What determines the growth of tropical reef fish larvae in the plankton: food or temperature? Mar Ecol Prog Ser 256:193-204

Miller TJ, Crowder LB, Rice JA, Marschall EA (1988) Larval size and recruitment mechanisms in fishes: towards a conceptual framework. Can J Fish Aquat Sci 45:1657-1670

Pepin P, Shears TH, Delafontaine Y (1992) Significance of body size to the interaction between a larval fish (Mallotus villosus) and a vertebrate predator (Gasterosteus aculeatus). Mar Ecol Prog Ser 81:1-12

Pressier EL, Bolnick DI, Benard MF (2005) Scared to death? The effects of intimidation and consumption in predatorprey interactions. Ecology 86:501-509

Searcy SP, Sponaugle S (2001) Selective mortality during the larval-juvenile transition in two coral reef fishes. Ecology $82: 2452-2470$

Editorial responsibility: Howard Browman (Associate Editorin-Chief), Storebø, Norway
Shima JS, Findlay AM (2002) Pelagic larval growth rate impacts benthic settlement and survival of a temperate reef fish. Mar Ecol Prog Ser 235:303-309

Sih A (1998) Game theory and predator-prey response races. In: Dugatkin LA, Reeve HK (eds) Game theory and animal behavior. Oxford University Press, Oxford, p 188-220

Sogard SM (1997) Size-selective mortality in the juvenile stage of teleost fishes: a review. Bull Mar Sci 60: $1129-1157$

Sogard SM, Olla BL (2002) Contrasts in the capacity and underlying mechanisms for compensatory growth in two pelagic marine fishes. Mar Ecol Prog Ser 243:165-177

Sponaugle S, Cowen RK (1997) Early life history traits and recruitment patterns of Caribbean wrasses (Labridae). Ecol Monogr 67:177-202

Sponaugle S, Pinkard DR (2004) Impact of variable pelagic environments on natural larval growth and recruitment of the reef fish Thalassoma bifasciatum. J Fish Biol 64:34-54

Sponaugle S, Grorud-Colvert K, Pinkard D (2006) Temperature-mediated variation in early life history traits and recruitment success of the coral reef fish Thalassoma bifasciatum in the Florida Keys. Mar Ecol Prog Ser 308: $1-15$

Steele MA, Forrester GE (2002) Variation in the relative importance of sublethal effects of predators and competitors on growth of a temperate reef fish. Mar Ecol Prog Ser 237:233-245

Stobutzki IC (1997) Energetic cost of sustained swimming in the late pelagic stages of reef fishes. Mar Ecol Prog Ser 152:249-259

Stobutzki IC, Bellwood DR (1994) An analysis of the sustained swimming abilities of presettlement and postsettlement coral-reef fishes. J Exp Mar Biol Ecol 175:275-286

Trippel EA, Kraus G, Koster FW (2005) Maternal and paternal influences on early life history traits and processes of Baltic cod Gadus morhua. Mar Ecol Prog Ser 303:259-267

Victor BC (1982) Daily otolith increments and recruitment in two coral reef wrasses, Thalassoma bifasciatum and Halichoeres bivittatus. Mar Biol 71:203-208

Vigliola L, Meekan MG (2002) Size at hatching and planktonic growth determine post-settlement survivorship of a coral reef fish. Oecologia 131:89-93

Wilson J, Osenberg CW (2002) Experimental and observational patterns of density-dependent settlement and survival in the marine fish Gobiosoma. Oecologia 130: $205-215$

Zar JH (1999) Biostatistical analysis. Prentice Hall, Upper Saddle River, NJ

Submitted: February 13, 2006; Accepted: May 1, 2006

Proofs received from author(s): October 31, 2006 